\title{
Intergenerational Communication Satisfaction and Age Boundaries in Bulgaria and the United States
}

\author{
Howard Giles • Christopher Hajek • Tolya Stoitsova • \\ Charles W. Choi
}

(C) The Author(s) 2010. This article is published with open access at Springerlink.com

\begin{abstract}
This paper examines Bulgarian and American young adults' perceptions of prior experiences of intergenerational communication. Irrespective of culture, as age of target increased from young adult to middle-aged and elderly adult, so did attributions of benevolence, norms of politeness and deference, and communicative respect and avoidance; conversely, attributions of personal vitality and communication satisfaction decreased linearly. However, American youth reported more of a tendency to avoid, but expressed more respect when communicating with, older adults than their Bulgarian counterparts. In both settings, young adults' avoidant communication with older people negatively, and the norm of politeness positively, predicted intergenerational communication satisfaction. In Bulgaria only, age stereotypes also predicted communication satisfaction whereas only in the USA was communicative respect a predictor.
\end{abstract}

Keywords Age norms $\cdot$ Age stereotypes $\cdot$ Respect $\cdot$ Deference $\cdot$ Communication satisfaction $\cdot$ Middle-age $\cdot$ Elder $\cdot$ Bulgaria

We are grateful to the Editors and two anonymous reviewers for their very helpful comments on a prior version of this paper.

H. Giles $(\bowtie) \cdot$ C. W. Choi

Department of Communication, University of California, Santa Barbara, CA 93106-4020, USA

e-mail: howiegiles@cox.net

C. W. Choi

e-mail: charleschoi@umail.ucsb.edu

C. Hajek

Department of Communication, University of Texas, One UTSA Circle, San Antonio, TX 78249-1644,

USA

e-mail: chris.hajek@utsa.edu

T. Stoitsova

Department of Mass Communication, New Bulgarian University, 21 Montevideo Str., Sofia 1618, Bulgaria

e-mail: tstoitsova@nbu.bg 


\section{Introduction}

A growing body of literature in the USA, and other Anglophone settings, has focused on the dynamics of communication in intergenerational relations (for overviews, see Harwood 2007; Nussbaum and Coupland 2004; Williams and Nussbaum 2001). Recently, the role of cultural variability has also been afforded considerable attention in the study of intergenerational communication practices (e.g., Giles 2004; Pecchioni et al. 2004). In this paper, we extend this work by investigating these issues in Eastern Europe - and Bulgaria more particularlywhere there is a paucity of work in this genre and social gerontological work more generally, and where intriguing comparative differences exist between Bulgaria and the USA.

Research in Western societies has indicated that young people construe communication with non-family older adults as often dissatisfactory and problematic (see Williams and Giles 1996; Hummert 2010). For instance, young adults report that they are often patronized by their elders who seem overly-nurturing and yet convey unfavorable stereotypes about their youth peer group (Giles and Williams 1994). In addition, elderly communicators can be perceived as nonaccommodative in that they are authoritarian, dismissive, complaining, pre-occupied with their own problems, and inattentive to the concerns of others (Coupland et al. 1991; Giles et al. 2003). Consequently, younger interlocutors are often conversationally avoidant of their elders but, nonetheless, report it necessary to be respectful (Ryan et al. 1992). For their part, many older people also feel victimized in being patronized and the recipients of ageist sentiments and in ways that do little to promote reports of their well-being (e.g., Giles et al. 2008; Giles and Gasiorek, 2010). This profile is cross-culturally resilient to the extent that it spans an array of different cultures having disparate religious and social traditions, including those relating to filial piety (e.g., McCann et al. 2003; Ota et al. 2007). Nonetheless, potent differences have emerged in that the intergenerational communication climate in Australia and the USA has been perceived to be more favorable than in the People's Republic of China, Hong Kong, Japan, and Taiwan (for review, see Giles et al. 2002). Hence, despite reporting higher norms of respect and obligation for older adults, East Asian young adults report more nonaccommodation from, and avoidance of, older adults than do their Western counterparts.

\section{The communicative-avoidance pattern}

Given the consistency of this communicative respect-plus-avoidance pattern from younger people, a theoretically-driven program of research across different cultures has emerged to investigate it further and, more specifically, the predictors (for young people) of satisfaction when talking with older adults. This work, originally conducted in the USA (McCann et al. 2005), subsequently embraced comparative data from South Africa and Ghana (Giles et al. 2005) as well as India (Giles et al. 2007). Given the intent is to extend this work into East Europe, before presenting more details of this prior cross-cultural work, we briefly overview relevant aspects of the Bulgarian scene.

As mentioned at the outset, and while there is a growing amount of social gerontological work in Central Europe (e.g., Rurik 2005; Csoboth 2006), this is very limited in Eastern European nations - apart, that is, from medical gerontology (e.g., Boyanova et al. 2003; Mihaylova et al. 2004). Most of the work that does exist in the more social spheres does not really inform the current inquiry (e.g., Bakracheva 2009; De Vos and Sandefur 2002; Silgidjian-Georgieva 1998) and, in any case, developmental interests in Bulgaria have tended to focus on intergenerational problems between adults and children or teenagers (Silgidjian 1978; Stoitsova 2001). Nonetheless, there are indications that there is an underrepresentation of older people in the Bulgarian media (Boshnakova 2009), and 
commentaries are not uncommon in social scientific texts about communication gaps between younger and older adults (e.g., Pachkova 2006; Prodanov 2006; Stoitsova 2006).

As most elsewhere, there has been a demographic revolution in Bulgaria, and the National Health Information Center estimates that the population aged over 60 years has increased from nearly $15 \%$ to $22 \%$ in the last 30 years (Bulgarian Population Aging 2002). Moreover, since becoming a member of the European Union in 2007, Bulgaria has been obliged to engage issues that are of general interest to this larger community, a crucial one of which relates to reforming its pensions and healthcare systems for older people (Agenda of the Meeting of the Committee on Culture of the European Parliament 2007). Indeed, "Bulgaria is not alone in this predicament, with 28 countries in Eastern Europe and the former Soviet Union facing the same challenge" (World Bank: Bulgarian Economy Threatened by Rapid Aging 2007). In tandem, and with gradually decreasing levels of unemployment over recent years (from $18 \%$ in 2003 to $7.70 \%$ in 2008 ), $46 \%$ of those now unemployed in Bulgaria are older adults between the ages of 50 and 60 years (Ilieva 2008).

The Bulgarian situation is of even greater interest given changes in Bulgaria's political status over the last 20 years. Since Bulgaria held free elections in 1990 and crafted its own Constitution the following year, those growing up there since that time have probably very different valueslet alone greater computer literacy - than those over 50 years old who would have lived through, and maybe accommodated to, decades of socialism. In other words, intergenerational chasms could be accentuated in such settings, not only because of acute communicative differentials in access to new technology, but also to potential differences in liberal values which could ferment further age stereotypes of inflexibility and being old-fashioned.

Bulgaria is, therefore, of particular theoretical interest to us as a comparative society in relation to the USA which itself has figured almost as the foundational anchor point in crosscultural research on intergenerational communication. However, Bulgaria is a particularly poignant culture to examine not only because of its general cultural values (together with, arguably, more traditional norms of filial piety) that are significantly less individualistic, more masculine, higher power distant with a stronger avoidance of uncertainty society than the USA (Davidkov 2009; Hofstede 2001) ${ }^{1}$, but because younger adults, unlike their older counterparts, have not been so vividly and politically socialized under the social constraints of a communist regime. For younger Bulgarians, we suspect a social differentiation away from more traditional conceptions of intergenerational solidarity and obligations that could have implications for what is acceptable communication between age groups. Indeed, the recent data from Davidkov (2009) cited above suggests that Bulgaria is more individualistic now that it was caricatured as being some 20 years ago and, potentially, it is the impact of a unique generation of young people that could be contributing to this trend.

Returning now to our core interest in predictors of intergenerational communication satisfaction cross-culturally, previous theoretical models (see Barker et al. 2004; Hummert et al. 2004) have suggested that age stereotypes and norms would be particularly potent variables alongside communicative respect and avoidance. Indeed, the prior work in the USA, Africa, and India had demonstrated that as a target increased in age from young

\footnotetext{
${ }^{1}$ In general, Americans were evaluatively more generous in their ratings than Bulgarian youth: the former conveyed more benevolence, respect, and communication satisfaction, irrespective of target age. In addition, and as with prior studies (e.g., Giles et al. 2005), the findings were only modestly impacted by gender to the extent that women were found to generally be less interpersonally avoidant and more socially normative - as would be expected from the extant communication and gender literature (see, for example, Stahlberg et al. 2007). However, they did report feeling the need to be more respectful of and deferent to their elders (see Laditka et al. 2004). The interested reader should contact the second author for more statistical information on the foregoing.
} 
adulthood, to middle-age, and to elderliness (see Giles et al. 2008), so did trait attributions of benevolence (e.g., kindness), and social norms of needing to be polite and deferent. However, attributions of so-called personal vitality (e.g., strong and flexible) and intergenerational communication satisfaction decreased linearly (Giles et al. 2005, 2007; McCann et al. 2005). Given this stable pattern across very different cultural contexts, and with the virtue of obtaining a fresh (more contemporary) American sample for this study as recommended in Giles et al. (2005), our first hypothesis was:

H1 American and Bulgarian young adults will attribute increasing benevolence, age norms of politeness and deference, and communicative respect and avoidance as people age from younger, to middle-aged, and older adulthood; the converse will be the case for attributed personal vitality and communication satisfaction with older adults.

Besides these communal effects, what differences might emerge between American and Bulgarian young people? Given the possibility (as above) of there being another layer of cultural division between the generations than, say, in the USA, together with prior studies showing more favorable intergenerational climates in Western European settings than elsewhere (see earlier), the following is predicted:

H2 When evaluating their past conversations with non-family older adults, young Bulgarians' reports of age norms, age stereotypes, communicative respect and avoidance, and communicative satisfaction will be less positive than their American counterparts.

The patterns of predictors in the prior studies (see Table 1) do suggest intriguing differences and contrasts although, that said, high communicative avoidance was responsible for dissatisfaction in all settings, whereas communicative respect was potent only in Africa. Interestingly, the African, and especially the Indian, contexts reflect more predictors than the USA, where stereotypes seem to have no impact despite their avowed and crucial role in western European models (e.g., Hummert et al. 2004). The summary Table 1 highlights a converse pattern, too, in that high stereotypic personal vitality predicted low satisfaction for the South African sample. In other words, while older adults who are social and cognitively active "are pleasing for young adults in Ghana,...[as in India]...they are perhaps socially intimidating in South Africa" (Giles et al. 2005, p. 217). This not insignificant nuance aside, the stability of communicative avoidance's impact across these very different cultures suggest that:

H3 Both American and Bulgarian young adults will report that high communicative avoidance will be associated with low satisfaction in communicating with older adults.

Table 1 Significant Regression Analyses from Prior Studies

\begin{tabular}{lllllll}
\hline & $\begin{array}{l}\text { USA } \\
\text { satisfaction }\end{array}$ & $\begin{array}{l}\text { India } \\
\text { satisfaction }\end{array}$ & $\begin{array}{l}\text { S. Africa } \\
\text { enjoyment }\end{array}$ & $\begin{array}{l}\text { S. African } \\
\text { satisfaction }\end{array}$ & $\begin{array}{l}\text { Ghana } \\
\text { enjoyment }\end{array}$ & $\begin{array}{l}\text { Ghana } \\
\text { satisfaction }\end{array}$ \\
\hline Communicative respect & & & ++ & & ++ & - \\
Communicative avoidance & - & - & - & - & - & \\
Normative politeness & - & & - & \\
Normative deference & + & & & + \\
$\begin{array}{l}\text { Stereotypic personal vitality } \\
\text { Stereotypic benevolence }\end{array}$ & + & & & \\
\hline
\end{tabular}

Although the two communication satisfaction items (of enjoyment and satisfaction) were highly correlated in the American and Indian settings, they were interestingly orthogonal in both the African ones 
What other predictors, then, might emerge (if any) for our Bulgarian sample? This is difficult to propose on the basis of the current literature and above discussion. Indeed, as Table 1 attests, each culture studied to date has rendered different profiles of what predicts young people's reports of communication satisfaction with older adults. Thus:

RQ1 Will Bulgarian adults exhibit different regression analyses for intergenerational communication satisfaction than documented elsewhere?

Finally, background data were provided on age boundary estimates in the prior American, African, and Indians studies (see also, Giles et al. 2000) and these were reported rather serendipitously as background data. Herein, however, they are considered of sufficient interest as to warrant elevation to the status of a research question. Toward that end, Table 2 summarizes young people's average perceptions of age boundaries across the aforementioned settings, and it can be seen that there is some inherent cross-cultural variability. Amongst other findings, Americans construe young adulthood as beginning and ending sooner than in Africa and India, but they report middle-age ending and elderliness beginning much later than these same settings. This led us to the following Research Question:

RQ2 How will young Bulgarian adults be positioned across these perceived age boundaries vis-à-vis Americans?

The present study, then, is the first to highlight Bulgarian intergenerational communication in comparative terms with the United States. Although gender had no real effects in prior research of this kind, given that we had adequate numbers and in response to the plea by Giles et al. (2005) to nonetheless attend to this variable, it was included in relevant analyses below.

\section{Materials and Methods}

Participants

In total, 399 undergraduate students $(54.40 \%$ male) from the two nations participated in the study, with a mean age of 21.45 years $(S D=2.67)$. The American sample consisted of 189 students (59.80\% males) from Santa Barbara, Southern California, with a mean age of 20.21 years $(S D=17.2)$. The ethnic Bulgarian sample consisted of 210 students from Sofia, with a mean age of 22.57 years $(S D=2.86)$.

Table 2 Mean Age Boundaries from Prior Studies

\begin{tabular}{lllll}
\hline & USA & India & South Africa & Ghana \\
\hline Young adulthood begins: & $16.60(2.26)$ & $17.55(1.78)$ & $18.46(3.05)$ & $19.78(5.76)$ \\
Young adulthood ends: & $28.24(5.57)$ & $32.75(7.06)$ & $29.96(8.22)$ & $31.10(8.09)$ \\
Middle age begins: & $32.67(5.82)$ & $33.33(5.96)$ & $28.63(7.60)$ & $31.34(6.82)$ \\
Middle age ends: & $55.85(7.85)$ & $51.22(7.09)$ & $45.02(12.90)$ & $45.37(8.10)$ \\
Elderly age begins: & $60.61(7.73)$ & $53.13(6.53)$ & $50.57(11.88)$ & $50.11(10.36)$ \\
\hline
\end{tabular}

Standard deviations in parentheses (with age ranges reported in original articles) 
Procedures and instruments

Using a within-subjects design, questionnaires asked participants to indicate their interaction experiences with non-family members or non-close friends regarding three target ages: young, middle-aged, and older adults. Participants were allowed to self-define these age ranges in accordance with RQ2. The original English versions of the questionnaires were independently back-translated into Bulgarian for the sample in that country; extra care was afforded semantic equivalence by our bilingual co-author (TS) in situ. Order of target age was counter-balanced through two questionnaire versions distributed randomly. In half of the questionnaires, young adults were placed first, followed by middle-age adults, and elderly adults last; this order was reversed in the other half.

For each target age, the questionnaires included measures of communication behaviors (i.e., how they actually behave during interactions with the target age), communication satisfaction with the age group, perceived stereotypes of the age group, and norms of respect (i.e., how they believe they should generally interact with the age group). All items for these scales (as well as their original sources) are provided in McCann et al. (2005). Confirmatory factor analyses were performed to determine that the sub-dimensions present in the current study were consistent with those present in the previous studies in regards to communication behaviors, stereotypes, and norms of respect scales. Separate analyses were conducted for the Bulgarian and American samples. Kaiser-Meyer-Olkin sampling adequacy measures for all factor analyses were greater than .70 (with the exception of the USA participants' reflections on younger people, communication behaviors at .65 and age stereotypes at .63) indicating the data were generally suitable for such analyses. The factor analyses revealed the same factors and general loading invariance across nations, and the same factors across target ages, for communication behaviors, age stereotypes, and norms of respect, and these were indeed similar to the factors revealed in past studies (e.g., Giles et al. 2005). Separate reliability coefficients (Cronbach's $\alpha$ ) for the resulting factors by each target were calculated for each sample (see below).

Communication behaviors Communication behaviors during interactions with the three target ages were assessed through 10 items. Similar to previous use of this scale (Giles et al. 2005; McCann et al. 2005), the confirmatory factor analyses revealed two dimensions: respect and avoidance; across the nations and target ages, the total variance explained in the analyses ranged from $44.66 \%$ to $57.03 \%$. The respect factor included six items (e.g., "I accommodated to them" and "I showed respect because of their age"), and the avoidance factor included two items (e.g., "I did not know what to say" and "I looked for ways to end the conversation"). Similar to previous uses of this scale (Giles et al. 2005), one item ("I held back my opinions") did not cohere with either factor and was, therefore, excluded. Across the age groups, reliability coefficients for both respect ( $\alpha=.68$ to .77 ) and avoidance ( $\alpha=.64$ to .78$)$ were acceptably high.

Age stereotypes Participants' stereotypes regarding each age group were assessed through a nine-item semantic differential scale. Similar to previous use of this scale, two factors were revealed by the factor analyses (total variance explained ranged from $41.61 \%$ to $57.31 \%$ ): personal vitality $(\alpha=.54$ to .74$)$ and benevolence $(\alpha=.67$ to .75$)$. The personal vitality factor included six items (e.g., attractive vs. unattractive, strong vs. weak, active vs. inactive), and the benevolence factor included three items (i.e., generous-ungenerous, kindunkind, and wise-unwise).

Norms of respect Participants' beliefs about how they should act with each age group were assessed through seven items (Gallois et al. 1999). Similar to previous use of this scale, two 
dimensions were revealed by the factor analyses (total variance explained ranged from $59.06 \%$ to $66.44 \%$ ). The politeness factor refers to norms people feel they should enact during interactions with the age group and included three items (e.g., "I should speak politely to them" and "I should listen patiently to them"). The deference factor refers to a restraint of behaviors during interactions and included four items (e.g., "I should restrain myself from arguing with them" and "I should hold back my opinions from them"). The deference item "I deferred to them" was excluded because it loaded highly on both factors. Reliability coefficients were sufficient for politeness $(\alpha=.75$ to .84$)$ and deference for middle and older aged targets $(\alpha=.60$ to .72$)$; however, reliability coefficients were lower for participants' reflections on younger targets $(\alpha=.53)$.

Communication satisfaction This was assessed with each age using two items: "I enjoyed my conversation with them" and "I was not satisfied with my conversation with them." The second item was reverse-coded so that greater scores indicated greater satisfaction and enjoyment. Although the reliability coefficient for participants' communication satisfaction with older people was relatively low $(\alpha=.53)$, the coefficients for satisfaction with younger and middle aged adults were acceptable at .71 and .70, respectively. Moreover, all correlations were significant $\left(p_{\mathrm{s}}<.001\right)$; therefore, the two items were combined to create one overall score of communication satisfaction for each target age. Where reliabilities in the foregoing were less than optimal, the factors were retained because of their theoretical significance.

\section{Results}

Hypotheses 1 and 2

Separate 3 (age target: young, middle-age, elderly adults) by 2 (nation: American and Bulgarian) by 2 (sex) repeated measures MANOVAs were conducted to identify differences in each of the dependent variables: communication behaviors, communication satisfaction, age stereotypes, and norms of respect. Both factors of each dependent variable were included in the same MANOVA. Target age was a within-subjects variable; nation and sex were between-subjects variables. For the sake of parsimony and focus, we were not so concerned with cultural differences in rating conversations in general, irrespective of target age. Nonetheless, such analyses were conducted (as indicated above) and the findings arising are merely glossed as are those pertaining to gender which, as in prior studies, did not impact the patterns emerging. ${ }^{2}$ In any case, across the MANOVAs, target age and the interaction between target age and nation were the most substantial predictors of differences in communication perceptions and behavior.

Communication behaviors The MANOVA for communication behaviors revealed a main effect for target age, $\lambda=.47, F(4,383)=108.28, p<.001, \eta^{2}=.53$, and an interaction between target age and nation, $\lambda=.90, F(4,383)=10.70, p<.001, \eta^{2}=.10$. The univariate analyses for the target age main effect revealed a staircase pattern in which ratings increase as target age increases from young adults to elderly adults for respect $\left(F=232.59, p<.001, \eta^{2}=.38 ; M \mathrm{~s}=\right.$ $4.20,4.95,5.74$, respectively) as well as for avoidance $\left(F=89.75, p<.001, \eta^{2}=.19 ; M \mathrm{~s}=2.66\right.$, $3.10,3.58$, respectively). The univariate analyses also showed that the interaction between

\footnotetext{
${ }^{2}$ Cultural values of Bulgaria vis-à-vis the USA across these four constructs are for the former 50, 50, 75, and 59 , whereas for the latter they are $91,62,40$ and 46, respectively.
} 
target and nation was significant for both respect and avoidance. Concerning respect $(F=$ $7.15, p<.001, \eta^{2}=.02$ ), although both Americans and Bulgarian participants reported greatest respect for elderly adults and lowest respect for young adults, Americans reported more respect for elderly adults as compared to the Bulgarian participants ( $M s=5.95,5.53$, respectively). Thus, the range regarding the staircase pattern for American participants was wider than the pattern for Bulgarian participants. The univariate analyses also showed that the interaction between target and nation was significant for avoidance $(F=21.25$, $\left.p<.001, \eta^{2}=.05\right)$. Although both Americans and Bulgarian participants reported greatest avoidance of elderly adults and lowest avoidance of young adults, Americans reported more avoidance of middle aged $(M=3.27)$ and elderly participants $(M=3.83)$ than did Bulgarians $(M s=2.96,3.34$, respectively). Conversely, American participants reported significantly less avoidance of younger adults than did Bulgarians ( $M s=2.49,2.85$, respectively). Regarding the interaction effect for target age and sex, the univariate analyses showed significance for respect only $\left(F=4.27, p<.01, \eta^{2}=.01\right)$.

Communication satisfaction The MANOVA for communication satisfaction yielded a significant main effect for target age, $\lambda=.88, F(2,391)=26.77, p<.001, \eta^{2}=.12$. The means for each target age revealed that satisfaction increased slightly between young and middle age, and significantly decreased with older target age $(M s=5.09,5.12,4.71$, respectively). The MANOVA also revealed an interaction between target age and nation, $\lambda=.97, F(2,391)=$ $6.83, p<.001, \eta^{2}=.03$. The means for target age by nationality showed that American participants reported decreasing satisfaction as target age increased $(M s=5.29,5.08,4.80$, respectively). Bulgarians showed a different pattern, in that communication satisfaction increased from younger to middle age, and then decreased again with older targets $(M s=4.86$, $5.13,4.59$, respectively). The univariate analysis showed that only the differences between Bulgarian and American participants'satisfaction with younger targets was significant.

Age stereotypes The MANOVA examining age stereotypes revealed main effects for target age, $\lambda=.25, F(4,387)=286.82, p<.001, \eta^{2}=.75$, and a significant interaction effect for target age and nation, $\lambda=.94, F(4,387)=6.72, p<.001, \eta^{2}=.07$. The univariate effects showed that ratings of both vitality $\left(F=416.44, p<.001, \eta^{2}=.51\right)$ and benevolence $(F=$ $432.75, p<.001, \eta^{2}=.52$ ) varied by target age. Again, staircase patterns emerged; ratings of vitality decreased as target age increased from young adults to elderly adults $(M s=5.19$, $4.71,3.20$, respectively), whereas ratings of benevolence increased as target age increased $(M s=3.70,5.10,5.50$, respectively). Univariate analyses showed significant interactions between nation and target age for both vitality $\left(F=9.43, p<.001, \eta^{2}=.02\right)$ and benevolence $\left(F=4.28, p<.01, \eta^{2}=.01\right)$. For vitality, Americans and Bulgarians rated middle-aged adults and older adults fairly equally, but the Americans rated younger adults higher than did Bulgarians (American $M s=5.42,4.67,3.14$; Bulgarian $M s=4.98,4.74,3.27$ ). For benevolence, Americans and Bulgarians rated younger and middle-aged adults fairly equally; however, Americans rated elderly adults substantially higher than did Bulgarians (American $M s=3.81,5.14$, 5.74; Bulgarian $M s=3.60$, 5.05, 5.27).

Norms of respect The MANOVA regarding norms of respect revealed main effects for target age, $\lambda=.34, F(4,390)=189.35, p<.001, \eta^{2}=.66$, as well as an interaction effect for target age and nation, $\lambda=.89, F(4,390)=12.46, p=.001, \eta^{2}=.11$. For the target age main effect, the staircase pattern again emerged for both politeness $\left(F=321.59, p<.001, \eta^{2}=.62\right)$ and deference $\left(F=292.78, p<.001, \eta^{2}=.43\right)$. Participants reported the least politeness with young adults and most with elderly adults $(M s=4.56,5.39,6.17$, respectively). Similarly, 
participants reported the least deference with young adults and the most with elderly adults $(M s=2.93,3.75,4.57$, respectively). Univariate analyses revealed that the interaction between target age and nation was significant for both politeness $\left(F=3.92, p=.02, \eta^{2}=.02\right)$ and deference $\left(F=30.02, p<.001, \eta^{2}=.07\right)$. Both Americans and Bulgarians reported fairly equal (and moderate) levels of politeness with young adults. In contrast, although both nations reported greatest levels of politeness with elderly adults, Americans reported greater politeness with middle-aged and elderly adults than did Bulgarians. (American $M s=4.62$, 5.58, 6.41; Bulgarian $M s=4.52,5.23,5.96$ ). A similar pattern emerged for deference. That is, both Americans and Bulgarians reported similar (albeit, low) levels of deference with young adults. In contrast, although both nations reported greatest levels of deference with elderly adults, Americans reported greater deference with middle-aged and elderly adults than did Bulgarians (American $M s=2.79,4.04$, 4.98; Bulgarian $M s=3.05,3.50,4.22$ ).

Overall, H1 was supported. Bulgarian young adults reported similar linear patterns in their stereotypes, norms of respect, communication behaviors, and communication satisfaction with the three target ages, as did Americans. H2 was also, for the most part, supported in that Americans reported stereotyped older adults as more personally vital and benevolent than Bulgarians - and also afforded them more respect. Yet, Americans also were more avoidant of older adults than were their Bulgarian counterparts.

\section{Hypothesis 3 and research question 1}

Because much of the literature on intergenerational communication focuses on that between young and older adults (see for example, Hummert 2010; Williams and Nussbaum 2001, although see Drury 2010 for research on teenagers and adults), and to replicate the analyses of McCann et al. (2005) and Giles et al. (2005, 2007) with additional cross-cultural data, separate multiple regressions were conducted. These were conducted to determine the predictors of communication satisfaction with elderly adults for each nation. Although causality cannot be tested from the current data, Tables 3 and 4 provide a summary of the regression results. ${ }^{3}$ When all communication behaviors, stereotypes, and norms of respect

\footnotetext{
${ }^{3}$ Again, although not a focus of the present report (but see Giles et al. 2005, 2007) as was the case in Giles et al. (2005), we did examine, by means of separate regression analyses, whether the two stereotype and two normative factors predicted the extent to which communicative respect and avoidance were reportedly enacted with older adults. Similarities (with one caveat) emerged across the two nations. Both politeness and deference significantly predicted respect toward elderly adults in the American data $(F[4,179]=14.74$, $p<.001, R^{2}=.25$ ): self-reported displays of respect increased as participants' beliefs regarding politeness and deference when interacting with elderly adults increased $(\beta s=.211, p<.05$ and $.325, p<.001$, respectively). This finding was reflected, even more so, in the Bulgarian data $\left(F[4,205]=37.89, p<.001, R^{2}=.43\right.$; corresponding betas $=.550, p<.01 \& .155, p<.05)$. In addition, the American and Bulgarian results were similar in that stereotypes of elderly adults (i.e., personal vitality and benevolence) did not predict respect shown with elderly adults during interactions. When predicting avoidance, the stereotypes of personal vitality $(\beta=-.162)$ and benevolence (beta $=-.150$, both $\left.\mathrm{p}_{\mathrm{s}}<.05\right)$, and the norm of deference $(\beta=.398, p<.01)$, were significant for the American data $\left(F[4,182]=11.64, p<.001, R^{2}=.20\right)$. That is, as participants' views of elderly adults increased in vitality and benevolence, avoidance during interactions with elderly adults decreased; avoidance also increased as the norm of deference increased. The vitality stereotype and deference norm results were similar for Bulgarian participants $\left(F[4,205]=8.05, p<.001, R^{2}=.14\right)$. That is, as Bulgarian participants' views of elderly adults increased in vitality $(\beta=-.190, p<.05)$, avoidance during interactions with elderly adults decreased. Moreover, and as with the American samples, avoidance increased as the norm of deference increased $(\beta=.309, p<.309, p<.01)$. In contrast to the American participants, however, as the norm of politeness decreased, avoidance increased $(\beta=-.248, p<.01)$. In sum, and as one might expect, age norms are important predictors of intergenerational communicative outcomes, albeit less potent in accounting for intergenerational satisfaction.
} 
Table 3 Regression Results for American Data

\begin{tabular}{|c|c|c|c|c|}
\hline & $\beta$ & $\mathrm{F}$ & df & $\mathrm{R}^{2}$ \\
\hline \multicolumn{5}{|c|}{ Communication satisfaction } \\
\hline Respect & $.169 *$ & $12.97 * *$ & $(6,176)$ & .31 \\
\hline Avoid & $-.551 * *$ & & & \\
\hline Vitality & .051 & & & \\
\hline Benevolence & .029 & & & \\
\hline Politeness & $.156^{*}$ & & & \\
\hline Deference & .058 & & & \\
\hline
\end{tabular}

$* p<.05, * * p<.001$

were used to predict communication satisfaction with elderly adults, only displays of respect, politeness, and avoidance, were significantly related to satisfaction in the American data. As respect and politeness increased and avoidance decreased, satisfaction in communicating with older people increased, thereby supporting H3. Somewhat similar results were found for Bulgarian participants in that avoidance and politeness were related to satisfaction in negative and positive ways respectively; however, unlike the Americans, the stereotype of vitality was also related to satisfaction. As the elderly target's vitality and politeness increased, communication satisfaction increased as well. Given this not only reflected a slightly different profile than the American sample and was, in addition, different from any of the African and Indian samples (Giles et al. 2005, 2007), RQ2 was answered in an interesting way.

\section{Research question 2}

Cross-cultural perceptions of age categories were examined to determine any differences in how cultures viewed when young, middle, and elderly ages begin and end. Separate ANOVAs were conducted on each age category question; differences were revealed across the two nations $(p<.01)$ with regard to when young adulthood begins and ends, and concerning when elderly age begins (see Table 5 for the means of each nation). American participants reported a later onset, and earlier termination, of young adulthood than did Bulgarian participants. American participants also reported a higher age for the beginning of older adulthood than did Bulgarians.

Table 4 Regression Results for Bulgarian Data

\begin{tabular}{|c|c|c|c|c|}
\hline & B & $\mathrm{F}$ & df & $\mathrm{R}^{2}$ \\
\hline \multicolumn{5}{|c|}{ Communication satisfaction } \\
\hline Respect & .117 & $17.23 * *$ & $(6,203)$ & .34 \\
\hline Avoid & $-.377 * *$ & & & \\
\hline Vitality & $.240^{* *}$ & & & \\
\hline Benevolence & .069 & & & \\
\hline Politeness & $.163 *$ & & & \\
\hline Deference & -.048 & & & \\
\hline
\end{tabular}

$* p<.05, * * p<.001$ 
Table 5 Perceived Age Boundaries

\begin{tabular}{llll}
\hline & Overall & U.S. American & Bulgarian \\
\hline Young adulthood begins: & $16.42(2.37)$ & $16.97(2.28)^{\mathrm{a}}$ & $15.92(2.34)^{\mathrm{b}}$ \\
Range & $7-25$ & $12-25$ & $7-21$ \\
Young adulthood ends: & $30.05(5.89)$ & $27.59(5.58)^{\mathrm{a}}$ & $32.23(5.29)^{\mathrm{b}}$ \\
Range & $17-50$ & $17-45$ & $18-50$ \\
Middle age begins: & $33.28(5.60)$ & $33.28(5.93)$ & $33.28(5.30)$ \\
Range & $18-51$ & $20-46$ & $18-51$ \\
Middle age ends: & $55.16(7.32)$ & $55.70(7.61)$ & $54.69(7.03)$ \\
Range & $32-70$ & $35-70$ & $32-70$ \\
Elderly age begins: & $58.60(7.54)$ & $61.71(6.95)^{\mathrm{a}}$ & $55.85(6.96)^{\mathrm{b}}$ \\
Range & $33-80$ & $40-80$ & $33-71$ \\
\hline
\end{tabular}

\section{Discussion}

The Bulgarian findings very much mirror the American data in terms of the staircase patterns for stereotypes, norms, communicative behaviors, and communicative satisfaction. More specifically, in Bulgaria (as found elsewhere), as people age, young adults confer more respect and deference, report providing more communicative respect, and accord them increasing benevolence. Yet the same time and confirming $\mathrm{H} 1$, the more people age, the more they were attributed lower personal vitality, the less satisfying conversations with them were reported, and the more they were avoided. Although these developmental trends are exaggerated in the USA, Bulgarian young adults are, and in many ways in accord with $\mathrm{H} 2$, more negatively disposed towards communicating with middle-aged and older people even in terms of the weakened age norms of politeness and deference - a finding that is perhaps surprising given Bulgaria is a higher power distant culture than the USA (as above). That said, unpredictably, less avoidant of older people than Americans. Indeed, there appears an indication of ambivalence among young Bulgarians as regards to how they should manage conversations with older people; they are less avoidant than Americans but, in tandem, reportedly less respectful and for reasons future research in that culture should determine. Indeed, perhaps there is some deep-rooted cultural dynamic that would explain youngsters" "grin-and-bear-it" approach to some older people in Bulgaria. Here, it is still very common for two or even three generations to live together "under one roof," such that young Bulgarians could not actually avoid communicating with elders - at least in the home- even if they wanted to. In the more individualistic USA, a reduced obligation to accommodate elders simply because of their age status has become more normalized. Interestingly also, peer-young targets were favored on some measures (i.e., more communicative satisfaction and personal vitality but less avoidance) by American youth more than their Bulgarian counterparts. This may align with other cross-cultural data showing that Americans have a greater sense of social identification with their age cohorts than do those in many other cultures (e.g., McCann et al. 2004; Uotinen 1998).

Once again as in other cultural settings studied, the most potent predictor of intergenerational communication satisfaction was communicative avoidance, thereby confirming H3. Clearly, given the ubiquity of this relationship, further research needs to attend to the social origins of the daunting finding that younger people often wish to avoid adults as they age from middle age to elderliness. However, for Americans this was - and 
with another, more contemporaneous, sample - not the only predictor as it was reported in prior studies (Giles et al. 2005, 2007). For the current sample, this time the norm of politeness and communicative respect also appeared as predictors. Interestingly enough, this still, nonetheless, affords USA youth with an internationally unique predictive profile (see Table 1) and also underscores the need for and value of collecting new data from cultural samples every decade or so. For Bulgarians, politeness also was predictive but so, too, was stereotypic personal vitality. Like the Ghanaian and Indian samples (but unlike the South African one), the link was positive, albeit with no effect for stereotypic benevolence. Why it is that there is a contrastive predictive profile for Bulgaria - and in a rather unique way for Africa and India (see Table 1 again) - is not at all clear and worthy of empirical pursuance. What is clear, though, is that what dictates reported satisfactory communication between younger and older adults - at least from the former's perspective - is quite culturally-determined and can change within any one culture at any time given prevailing social circumstances.

In this study (as with its predecessors), participants were invited to create their own subjective boundaries of age groupings. In response to RQ2, cross-cultural differences were evident in that Americans construe young adulthood as beginning a little later, but ending earlier, than Bulgarians. Regarding the former finding, it could be relevant to point out that most southern Californian students (at least in the present institution) live away from home, are more dependent on their parents' support and, now in the current economic climate, more likely to return to live with parents after graduation. The tendency that Bulgarian youth find work earlier than Americans, due to the social and economic changes of the last 20 years, could help explain this particular phenomenon. Nowadays, more then $80 \%$ of Bulgarian young adults have parttime or full-time jobs and it is very difficult for parents to afford all their children's expenses at university, thereby forcing more and more youth into the labor market.

Also, it should be noted that the boundaries between younger and middle-aged categories can be rather experientially fuzzy (see Tables $2 \& 5$ ) and that Bulgarians, along with other cultures, appear to have a less clear boundary at this juncture than the USA and construe elderliness typically much later (see Giles et al. 2000). Indeed, it could well be that the meanings of middle-age are quite different between cultures - and for different reasons.

These findings should be interpreted in light of some limitations, not least of which is the reliance, as before, on student populations (for studies on community-dwelling elders, see for example, LaTourette and Meeks 2001; Ryan et al. 2000). Additionally, a few of the factors yielded low reliabilities, such as older communication satisfaction and younger avoidance. In future research, the range of items per factor needs to be extended, together with elaborated instruments for age stereotypes, age norms and communicative behaviorsparticularly as they inform others' perceived messages such as elders' nonaccommodativeness (Giles et al. 2003). Second and relatedly, there is a dire need to have social constructs and dependent measures emerge beforehand from local informants themselves in their own language (see Zhang and Hummert 2001). And in addition, the communication satisfaction factor was assessed using only two items. Although consistent with previous research (Yeh et al. 1998), validated scales of communication satisfaction should be utilized in the future to enable stronger conclusions regarding predictors of it. Third, although perceptions of communicative behaviors were assessed, methodologies employing observational analyses should be incorporated to verify participants' accounts of the behaviors enacted during ongoing interactions with each of the target ages. Armed with the social constructs inherent in the work reported here, it seems a priority for future research to determine their roles (as well as reciprocal consequences) in actual intergenerational exchanges of different kinds. Finally, and as underscored in Barker et al. (2004), there would be mileage in exploring the "group vitalities" of different age groups (see Giles et al. 2000) in that "various dimensions 
of occupational and functional deployment should be incorporated as critical elements of a generation's social efficacy (as well as, for some in contrast, their perceived level of social threat)" (Giles et al. 2005, p. 198). In this regard, recall the higher unemployment of older Bulgarians mentioned earlier.

Despite these constraints, we have provided valuable data with an under-studied population in intergenerational communication research, and one setting - together with other Eastern European settings - that is deserving of more focal empirical and theoretical scrutiny. Yet again, we have not been able to locate a cultural setting where the communication climate for older people holds any appreciable advantage for them. Clearly, there is a need to investigate what factors incline young people to avoid their elders (as in the USA) - or when they are less avoidant might be less respectful (as in Bulgaria) - and what adverse outcomes might emerge as a consequence. From this study, educational interventions promoting intergenerational contact suggest themselves the extent of the need to convey more respect to and politeness for older people in addition to appreciating their individual personal vitalities (Ryan et al. 1995) and suggest the gains to be obtained from, rather the avoidance of, quality interactions with them. Our international data suggest that in different nations such programs can be profitably finetuned so as to direct attention to the cultural nuances found to uniquely profile each setting (see Table 1 again). However, and as always, interventions need to be bilateral and future work should incorporate middle-aged and elderly respondents into the empirical fray.

Open Access This article is distributed under the terms of the Creative Commons Attribution Noncommercial License which permits any noncommercial use, distribution, and reproduction in any medium, provided the original author(s) and source are credited.

\section{References}

Agenda of the Meeting of the Committee on Culture and Education of the European Parliament on 16-17 July 2007, Brussels: "Strengthening the connections between generations", p. 3. COM (2007)0244. Retrieved on Nov. 22, 2008 from http://www.europarl.europa.eu/meetdocs/2004_2009/documents/pv/ 676/676788/676788bg.pdf (in Bulgarian)

Bakracheva, M. (2009). Identity in three steps: Statuses of identity and intimacy, life satisfaction and happiness in mature ages. Sofia: Paradigma. in Bulgarian.

Barker, V., Giles, H., \& Harwood, J. (2004). Inter- and intragroup perspectives on intergenerational communication. In J. F. Nussbaum \& J. Coupland (Eds.), Handbook of communication and aging research (2nd ed., pp. 139-166). Mahwah: Erlbaum.

Boshnakova, D. (2009). What is hidden behind the newspapers' content. In T. Stoitsova \& D. Boshnakova (Eds.), What is written in our daily newspapers? One year into the European Union (pp. 32-55). Sofia: New Bulgarian University Press. in Bulgarian.

Boyanova, L., Katsarov, N., Gergova, G., Nikolov, R., \& Derejian, S. A. (2003). Helicobacter pylori infection in elderly Bulgarian patients. Journal of Medical Microbiology, 52, 1131-1133.

Bulgarian Population Aging, data show. (2002). Retrieved on Nov. 18, 2008 from http://www.novinite.com/ view_news.php?id=7615

Coupland, N., Coupland, J., \& Giles, H. (1991). Language, society, and the elderly: Discourse, identity and aging. Oxford: Blackwell.

Csoboth, C. T. (2006). Health of aging women in Hungary. In G. M. Backes, V. Lasch, \& K. Reimann (Eds.), Gender, health and aging (pp. 125-137). Berlin: Springer.

Davidkov, Ts. (2009). National and organizational cultures. Sofia: Sofia University Publishing House. (in Bulgarian language).

De Vos, S., \& Sandefur, G. (2002). Elderly living arrangements in Bulgaria, The Czech Republic, Estonia, Finland, and Romania. European Journal of Population, 18, 21-38. 
Drury, J. (2010). Identity dynamics in adolescent-adult communication. In H. Giles, S. A. Reid, \& J. Harwood (Eds.), The dynamics of intergroup communication (pp. 53-64). New York: Lang.

Gallois, C., Giles, H., Ota, H., Pierson, H. D., Ng, S. H., Lim, T.-S., et al. (1999). Intergenerational communication across the Pacific Rim: The impact of filial piety. In J.-C. Lasry, J. Adair, \& K. Dion (Eds.), Latest contributions to cross-cultural psychology (pp. 192-211). Lisse: Swets \& Zeitlinger.

Giles, H. (Ed.). (2004). Communication climates and practices. Journal of Cross-Cultural Gerontology, 19(4).

Giles, H., \& Williams, A. (1994). Patronizing the young: forms and evaluations. International Journal of Aging and Human Development, 39, 33-53.

Giles, H., \& Gasiorek, J. (2010). Intergenerational communication practices. In K. W. Schaie \& S. Willis (Eds.), Handbook of the psychology of aging (7th ed.). New York: Elsevier, in press.

Giles, H., Noels, K., Ota, H., Ng, S. H., Gallois, C., Ryan, E. B., et al. (2000). Age vitality across eleven nations. Journal of Multilingual \& Multicultural Development, 21, 308-323.

Giles, H., McCann, R. M., Ota, H., \& Noels, K. A. (2002). Challenging intergenerational stereotypes: Across eastern and western cultures. In M. S. Kaplan, N. Z. Henkin, \& A. T. Kusano (Eds.), Linking lifetimes: A global view of intergenerational exchange (pp. 13-28). Honolulu: University Press of America, Inc.

Giles, H., Noels, K., Williams, A., Ota, H., Lim, T.-S., Ng, S. H., et al. (2003). Intergenerational communication across cultures: Young people's perceptions of conversations with family elders, nonfamily elders, and same-age peers. Journal of Cross-Cultural Gerontology, 18, 1-30.

Giles, H., Makoni, S., \& Dailey, R. M. (2005). Intergenerational communication beliefs across the lifespan: Data from Ghana and South Africa. Journal of Cross-Cultural Gerontology, 20, 191-211.

Giles, H., Dailey, R. M., Sarkar, J. M., \& Makoni, S. (2007). Intergenerational communication beliefs across the lifespan: Comparative data from India. Communication Reports, 20, 75-89.

Giles, H., Ryan, E. B., \& Anas, A. P. (2008). Perceptions of intergenerational communication by young, middle-aged, and older Canadian adults. Canadian Journal of Behavioral Science, 40, 121-130.

Harwood, J. (2007). Understanding communication and aging. Thousand Oaks: Sage.

Hofstede, G. (2001). Cultures consequences: Comparing values, behaviors, institutions, and organizations across nations. Thousand Oaks, CA: Sage.

Hummert, M. L. (2010). Age group identities, stereotypes, and communication. In H. Giles, S. A. Reid, \& J. Harwood (Eds.), The dynamics of intergroup communication (pp. 42-52). New York: Lang.

Hummert, M. L., Garstka, T. A., Ryan, E. B., \& Bonnesen, J. L. (2004). The role of age stereotypes in interpersonal communication. In J. F. Nussbaum \& J. Coupland (Eds.), Handbook of communication and aging research (2nd ed., pp. 91-114). Mahwah: Erlbaum.

Ilieva, K. (2008). Half of the unemployed over 50 years-Discriminated. Retrieved on Dec. 2, 2008 from http://international.ibox.bg/news/id_1511826875

Laditka, S. B., Fischer, M., Laditka, J. N., \& Segal, D. R. (2004). Attitudes about aging and gender among young, middle age, and older college-based students. Educational Gerontology, 30, 403-421.

LaTourette, T., \& Meeks, S. (2001). Perceptions of patronizing speech by older women in nursing homes and in the community: Impact of cognitive ability and place of residence. Journal of Language and Social Psychology, 19, 66-82.

McCann, R. M., Ota, H., Giles, H., \& Caraker, R. (2003). Perceptions of intra- and intergenerational communication among adults in Thailand, Japan, and the U.S.A. Communication Reports, 16, 1-23.

McCann, R., Kellermann, K., Giles, H., Gallois, C., \& Viladot, M. A. (2004). Cultural and gender influences on age identification. Communication Studies, 55, 88-105.

McCann, R. M., Dailey, R. M., Giles, H., \& Ota, H. (2005). Beliefs about intergenerational communication across the lifespan: Middle age and the roles of age stereotyping and filial piety. Communication Studies, $56,293-311$.

Mihaylova, E. N. A., Ivanova, M., Michailova, S., Penkova, K., \& Baltadjieva, D. (2004). Immunological markers contributing to successful aging in Bulgarians. Experimental Gerontology, 39, 637-644.

Nussbaum, J. F., \& Coupland, J. (Eds.). (2004). Handbook of communication and aging research (2nd ed.). Mahwah: Erlbaum.

Ota, H., Giles, H., \& Somera, L. B. (2007). Culture and communication across age groups: People's perceptions of intra- and intergenerational communication in Japan, the Philippines, and the United States. Communication Studies, 58, 173-188.

Pachkova, P. (2006). Crisis intergenerational distance. In E. Marinova (Ed.), Moral socialization of children and youth in Bulgaria (pp. 248-259). Veliko Turnovo: Faber. in Bulgarian.

Pecchioni, L. L., Ota, H., \& Sparks, L. (2004). Cultural issues in communication and aging. In J. Nussbaum \& J. Coupland (Eds.), Handbook of communication and aging research (pp. 167-207). Mahwah: Erlbaum.

Prodanov, V. (2006). From modern to post-modern moral socialization of children and youth. In E. Marinova (Ed.), Moral socialization of children and youth in Bulgaria (pp. 13-36). Veliko Turnovo: Faber. in Bulgarian.

Rurik, I. (2005). Revaluation of lifestyle and nutrition among Hungarian elderly. Orvosi Hetilap, 146, $1583-1585$. 
Ryan, E. B., Kwong See, S., Meneer, W. B., \& Trovato, D. (1992). Age-based perceptions of language performance among young and older adults. Communication Research, 19, 423-443.

Ryan, E. B., Meredith, S. D., MacLean, M. J., \& Orange, J. B. (1995). Changing the way we talk with elders: Promoting health using the communication enhancement model. International Journal of Aging and Human Development, 41, 89-107.

Ryan, E. B., Kennaley, D. E., Pratt, M. W., \& Shumovich, M. A. (2000). Evaluations by staff, residents, and community seniors of patronizing speech in the nursing home: Impact of passive, assertive, or humorous responses. Psychology and Aging, 15, 272-285.

Silgidjian, A. (1978). Personality of the teenager. Sofia: South Publishing House. in Bulgarian.

Silgidjian-Georgieva, A. (1998). Self-concept and psychosocial identity: Life transition to maturity. Sofia: South Publishing House. in Bulgarian.

Stahlberg, D., Braun, F., Irmen, L., \& Sczesny, S. (2007). Representation of the sexes in language. In K. Fiedler (Ed.), Social communication (pp. 163-187). New York: Psychology.

Stoitsova, T. (2001). Psychology. (Textbook for 9th grade in secondary schools in Bulgaria). Sofia: Prosveta. in Bulgarian.

Stoitsova, T. (2006). About children, youth, violence and mass media. In E. Marinova (Ed.), Moral socialization of children and youth in Bulgaria (pp. 164-173). Veliko Turnovo: Faber. in Bulgarian.

Uotinen, V. (1998). Age identification: A comparison between Finnish and North American cultures. International Journal of Aging and Human Development, 46, 109-124.

Williams, A., \& Giles, H. (1996). Retrospecting intergenerational conversations: The perspective of young adults. Human Communication Research, 23, 220-250.

Williams, A., \& Nussbaum, J. F. (2001). Intergenerational communication across the lifespan. Mahwah: Erlbaum.

World Bank: Bulgarian Economy Threatened by Rapid Aging. (2007). Retrieved on Nov. 18, 2008 from http://www.novinite.com/view_news.php?id=82088 (in Bulgarian)

Yeh, K.-H., Williams, A., \& Maryuama, M. (1998). Approving and disapproving grandmothers and strangers: Young Taiwanese and American comparisons. Journal of Asian Pacific Communication, 8, 125-149.

Zhang, Y. B., \& Hummert, M. L. (2001). Harmonies and tensions in Chinese intergenerational communication: Younger and older adults' accounts. Journal of Asian Pacific Communication, 11, 203-230. 